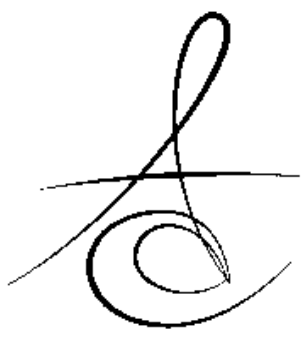

\section{OSTEOPETROZISLİ BİR HASTANIN PROTETİK REHABİLİTASYONU: OLGU SUNUMU}

\author{
PROSTHETIC REHABILITATION OF A PATIENT WITH \\ OSTEOPETROSIS: A CASE REPORT ${ }^{\ddagger}$
}

Dt.İmran KOÇAK*

Prof. Dr.Gözlem CEYLAN ${ }^{*}$

\author{
Makale Kodu/Article code: 2836 \\ Makale Gönderilme tarihi; $\quad 03.05 .2016$ \\ Kabul Tarihi: 10.08 .2016
}

Doç. Dr.Göknil ERGÜN KUNT*

\section{öz}

Bu olgu sunumunda osteopetrozis vakası olan bir hastanın maksiller tam protezinin manyetik ataşman sistemi ile oral rehabilitasyonu sunulmuştur. 35 yaşında osteopetrozis sendromu olan bayan hasta, maksiller tam protezindeki estetik problem nedeniyle kliniğimize başvurmuştur. Klinik ve radyografik muayene sonrası hasta değerlendirilmiştir. Yapılan klinik muayenede hastanın manyetik ataşman sistemine sahip maksiller protezini 15 yıldır kullandığı görülmüştür. Bu olguda hasta erken yaşta dişlerinin hepsini kaybetmiştir. Yalnızca sol üst 2. premolar dişi bulunmaktadır ve ağız içi muayenesi değerlendirildiğinde o diş kökü üzerinde mevcut bulunan manyetik ataşman desteği ile tam protezini uzun dönem kullandığı görülmüştür. Hastanın tam protezinin benzer manyetik sistem kullanılarak yenilenmesine karar verilmiştir. Hastaya mandibular bölgede bulunan osteosklerozis ve skar dokusu nedeniyle mandibular tam protez yapılamamıştır. Tedavi sonrasını takiben hasta birinci hafta, birinci ay ve üçüncü aylarda kontrol edilmiştir. Manyetik ataşmanların retansiyonu zamanla azalsa da, bu vakada hasta herhangi bir problem yaşamamıştır. Manyetik ataşmanlı sistemler diğer ataşman sistemleriyle karşılaştırıldığında retansiyon özelliği olarak yetersiz olduğu görülebilir.

Anahtar Kelimeler: Osteopetrozis, protetik rehabilitasyon, manyetik ataşman.

\section{ABSTRACT}

This clinical report describes the oral rehabilitation of a osteopetrosis patient with maxillary prosthesis with magnetic attachment system. A-35-year old female patient, who suffered from osteopetrosis, came to our clinic due to the esthetic problem of the maxillary complete denture. After clinical and radiographic examination, the patient's demands were evaluated. In the clinical examination it was seen that the patient was still using the maxillary complete denture with the magnetic attachment system for 15 years. The patient had no problems in terms of magnetic retention but she had complaints about her prosthesis aesthetic. We decided to make a new prosthesis to the patient with the same magnetic attachment system. Mandibular complete denture couldn't be constructed due to osteosclerosis and scar tissue in the mandibular area. Patient was clinically controlled during the first week, first month and third month following denture insertion. Inspite the decrease in retention of magnetic attachments, the patient had used the prosthesis for a long time with no complaints. In terms of retention characteristics compared to other attachment systems, magnetic systems may be found insufficient in retention.

Keywords: Osteopetrosis, prosthetic rehabilitation, magnetic attachments.

\footnotetext{
*Ondokuz Mayıs Üniversitesi Diş Hekimliği Fakültesi Protetik Diş Tedavisi Anabilim Dalı, 


\section{GİRIŞ}

Osteopetrozis (Albers-Schomberg hastalığı) büyümeyi ve kemik şekillenmesini etkileyen bir grup hastalığa verilen isim olup, kemik rezorpsiyonu kusuru nedeniyle oluşan yaygın kemik sklerozu ile karakterize nadir görülen kalıtımsal bir hastalıktır ${ }^{1,2}$. Radyografik olarak kemik dansitesinin artması ve kemik iliğinin azalması ile karakterizedir ${ }^{3}$. Hastalığa yol açan neden osteoklast işlevlerindeki defekttir. Kemik rezorpsiyonun azalması nedeniyle oluşan osteoskleroz, kemik iliği mesafelerinin yavaş yavaş ortadan kalkmalarına yol açar ${ }^{4}$.

$\mathrm{Bu}$ hastalarda çene ve diş problemlerinin tedavisi diş hekimi tarafından dikkatli değerlendirilmeli, tedavi süreçlerinde özel tedavi prosedürleri uygulanmalıdır. Dişlerde sürme güçlüğü, mine hipoplazisi, yüksek çürük hızı, kök oluşumunun durması, malforme dişler, lamina dura kalınlığı bu tür hastaların patolojik değişiklikleridir ${ }^{5,6,7}$.

Diş hekimlerinin osteopetrozis hastalığının teşhisinde hastalarda dikkat edecekleri özellikler şu şekilde sınıflandırılmıştır: Anemi, kırığa kolay eğilim, karakteristik yüz, kraniyel sinirlerde bası ve hissizlik, diş ve çene kemikleri radyograflarında alışılmamış kemik dansitesi $i^{8,9}$.

Mıknatıslar hareketli protezlerde bağlantıyı sağlamak amacıyla doğal diş kökü veya dental implantlardan destek alınarak kullanılan tutucu elemanlardır. İmplant veya diş kökü destekli hareketli protezler ve çene yüz protezleri gibi yaygın kullanım alanları vardır ${ }^{10}$.

Protezlerin tutuculuğu için yıllardır mıknatıslar kullanılmaktadır. Benzer kutupların birbirini itmesi ve zıt kutupların birbirini çekmesi prensibleriyle kulanılmışlardır ${ }^{11}$. Magnet yapımında önceleri aluminyumnikel-kobalt (Al-Ni-Co) diş hekimliğinde uzun yıllar kullanılmıştır ${ }^{10}$. Fakat yeterli manyetik tutuculuğun sağlanabilmesi için büyük boyutlarda olması gerektiğinden kullanımına devam edilmemiştir ${ }^{12}$. Yapılan çalışmalar paladyum-kobalt-nikel (Pd-Co-Ni) alaşımının manyetik ve fiziksel özellikleri açısından ayrıca korozyona en dirençli alaşım olduğunu göstermiştir ${ }^{11,13}$.

Manyetik ataşmanlar genellikle mandibular diş üstü protezlerin tutuculuğu için kullanılmaktadır ${ }^{14}$. Bu ataşmanların basitlik, düşük maliyet, kolay uyumlanma özelliği, tekrar kullanılabilme kolaylığı, protezin kendi mesafelerde hareketini takiben tekrar eski yerini alması, lateral ve rotasyonel protez hareketlerine izin vermesi, destek dişlere gelen travma potansiyelinin düşük olması, protezlerde besleme işleminin kolay olması, kendi yapısında mevcut olan kuvvet kırıcılık, değişmeyen tutuculuk kuvveti ve bunun sonucunda kullanıma bağlı olarak uyumlama gerektirmeyişi üstünlükleri arasında sayılabilir ${ }^{11,12,13}$.

Osteopetrozis gibi erken diş kayıplarına sebep olan kalıtımsal hastalıklarda kalan az sayıda dişlerin kemik desteği ve sağlığı iyi ise protezin tutuculuk, stabilitesi ve kalan dokuların sağlığı için manyetik ataşman desteğinin üst çene tam protez planlamasında kullanılabileceği, stabil ve retantif bir restorasyon olabileceği öngörülebilir.

$\mathrm{Bu}$ olgu sunumunda, manyetik ataşman destekli maksiller tam protezdeki estetik kayıp ve diş kırığı şikayetleri nedeniyle kliniğimize başvuran 35 yaşında bayan hastanın üst çene protezinin yeniden diş üstü protezle rehabilitasyonu sunulmuştur.

\section{OLGU SUNUMU}

35 yaşında bayan hasta, maksiller tam protezindeki diş kırığı ve estetik problemleri nedeniyle Ondokuz Mayıs Üniversitesi, Diş Hekimliği Fakültesi, Protetik Diş Tedavisi Kliniği'ne başvurmuştur. Hastanın medikal, dental ve sosyal anamnezleri alındıktan sonra klinik ve radyolojik muayeneleri yapılmıştır(Resim 1).

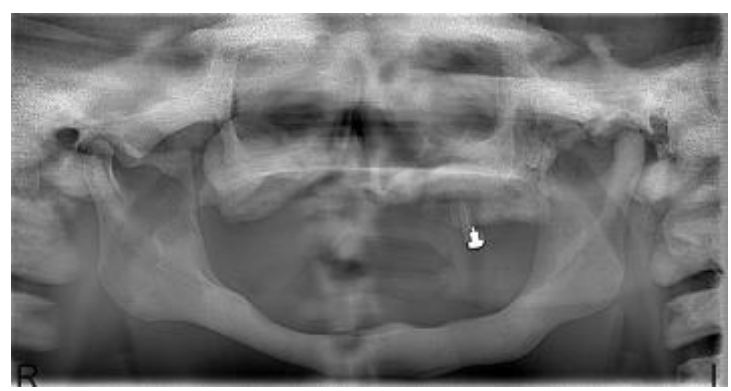

Resim 1. Panaromik radyografi görüntüsü.

Osteopetrozis hastalığında görülen, yüz ve baş bölgesinde anormal görünüm, büyüme geriliği, duyma problemleri, kemik fraktürleri, hipodonti gibi karakteristik bulguları olan hastanın bütün dişlerini osteopetrozis nedeniyle kaybettiği, sadece üst çenede sol kanin ve 2. premolar dişinin kaldığı öğrenildi. Fakültemize tedavi amacıyla başvuran hasta 15 sene önce mevcut dişlerin kök kanalı içerisine özel olarak hazır- 
lanan yuvaya manyetik ataşman yerleştirildiğini ve maksiller tam protez yapıldığını belirtmiştir. Bir sene sonra hasta sol kanin diş kökünün çekilmesiyle tek dişte bulunan manyetik destek ile protezini 15 yıl kullandığını ifade etmiştir. Alt çenede çekimler sonrası gelişen kemik nekrozları ve osteomyelit nedeniyle hasta plastik cerrahide ameliyat olmuş, yetersiz bazal kemik ve skar dokusu nedeniyle alt çene tam protezi yapıla- mamış ve hasta yıllarca sadece üst çene tam protezini kullanmıştır.

Yaptığımız radyolojik ve klinik muayenede sol 2 . premolar diş kökünün kemik desteğini kaybetmediği kanal tedavisinde ve manyetik tutucu bağlantısında genel olarak herhangi bir uyumsuzluk olmadığı görüldü. Fakat ağız içerisindeki manyetik ataşman üzerinde plak ve korozyon mevcuttu (Resim 2). Hastanın eski protezinde santral dişte kırık ve protezin içerisinde bulunan inaktif manyetik ataşmanda korozyon görülmekteydi (Resim 3).

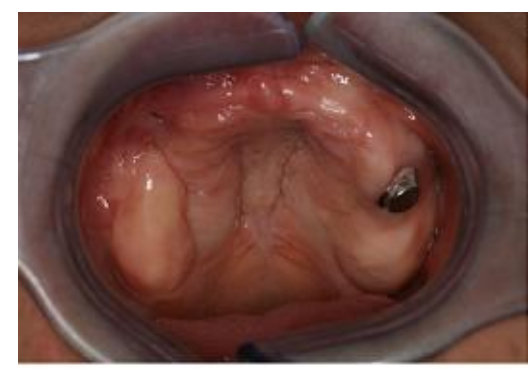

Resim 2. Maksiller okluzal ağız içi görünümü.

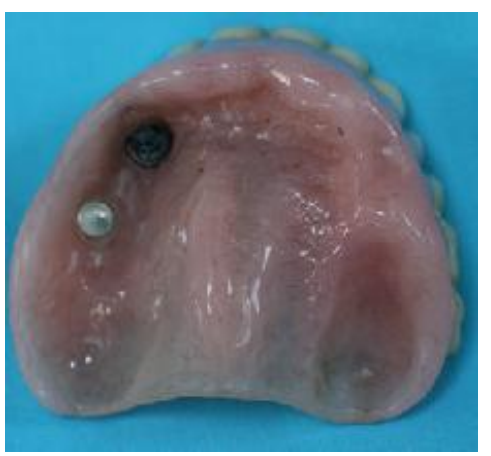

Resim 3. Protez içerisindeki manyetik ataşmanların görünümü.

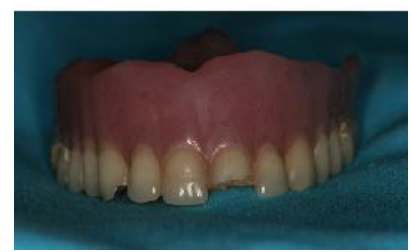

Resim 4. Eski protezde santral dişte kırık

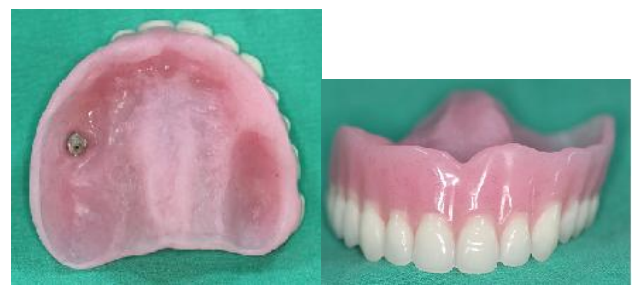

Resim 5. Yenilenen maksiller tam protez görüntüsü.

Hem hastanın estetik beklentilerini karşılamak, hem de doku desteğinden faydalanarak kemik rezorpsiiiyonunun önüne geçerek daha stabil bir protez yapmak amacıyla hastanın protetik rehabilitasyonu yapıldı.

Hastaya implant destekli protetik tedavi seçeneği sunulmuş ve cerrahi konsültasyon yapılmıştır, ancak hastanın mevcut reziduel kretlerindeki aşırı rezorpsiyon ve kemiğin kırılgan olması nedeniyle implant tedavisi yapılamadı. Ayrıca alt çene kemiğindeki skar dokusu ve bazal kemiğin rezorbsiyonu konvansiyonel tam protez yapılmasına da engel oldu. Bu nedenle hastaya benzer ataşman sistemiyle maksiller tam protez yapıldı.

Tam protez yapımında kullanılacak modellerin elde edilmesi için geri dönüşümsüz hidrokolloid ölçü maddesi (Palgat QuickPlus, 3M ESPE, Seefeld, Germany, lot:230579) kullanılarak anatomik ölçü alındı. Anatomik ölçüden elde edilen model üzerinde hazırlanan kişisel kaşık ile hastanın fonksiyonel kenar şekillendirme işlemi çubuk stenç (Kerr,Salerno, Italia, lot:5669531) ile yapıldı. Çinko oksit ojenol kullanılarak fonksiyonel ölçü (SS White, Impression Paste, Gloucester, England, lot:571319) alındı. Bu ölçü ile elde edilen ana model üzerinde hazırlanan kaide yardımı ile hastanın alt üst çene ilişkisi kayıtları alınarak diş dizimi yapıldı. Isı ile polimerize olan bir akrilik rezin (Meliodent, Heraeus Kulzer GmbH\&Co.KG, Germany, lot:1289) ile maksiller tam protez bitirildi. Manyetik ataşmanın protez parçası indirekt yöntem ile protez içerisine yerleştirildi (Resim 4). Hastanın maksiller tam

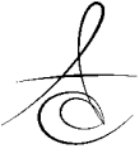


protezi tek manyetik ataşman desteği kullanılarak bitirildi (Resim 6).
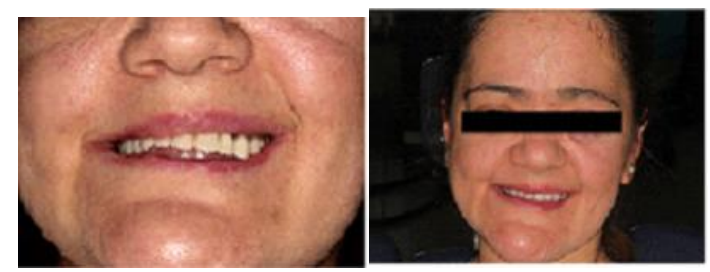

Resim 6: Hastanın tedavi öncesi ve sonrası görünümü.

\section{TARTIŞMA}

Osteopetrozis, hastalarda çene kemikleri ve tüm vücut kemiklerinde kemik rezorpsiyonu artışına neden olan, kemik dansitesi ile karakterize nadir görülen bir hastalıktır ${ }^{4}$. Erken dönemde meydana gelen diş kayıplarının tedavisi için kalan dişlerin sağlığı ve prognozu iyi değerlendirilmelidir. Çene kemiklerindeki kırılganlık ve çekim sonrası gelişebilen enfeksiyonlar sebebiyle diş kayıpları sonrası protetik rehabilitasyon için dental implant kullanımı mümkün olamayabilmektedir.

Ostepetrozis gibi kalıtımsal kemik hastalığı olan dişlerini kaybetmiş hastaların protetik rehabilitasyonunda ağızda kalan dişlerde kron harabiyeti fazla ve kök desteği iyi ise manyetik ataşmanlar kullanılması uzun dönemde protez stabilizasyonu için alternatif bir tedavi seçeneği olabilir.

Manyetik ataşmanlar genellikle alt çene protezlerin tutuculuğu için kullanılmaktadır. Pek çok araştırmacı magnetlerin kullanım prosedürlerini bu şekilde tanımlamış ${ }^{15,16,17}$, ve hastaların protezlerinden genel beklentilerini büyük ölçüde karşıladığını rapor etmişlerdir ${ }^{18}$.

Magnetlerin diğer tutucu ataşman sistemlerine göre daha kısa süreli bir kullanım ömrüne sahip olmasının sebebi, çoğu araştırmacıya göre potansiyel ömrünün ağızda kalma süresiyle orantılı olmasıdır ${ }^{14}$. Uzun dönem kullanım sonrası manyetik tutuculuk azalması, magnet kayıpları, ağız sıvıları ile temas nedeniyle manyetik ataşmanlarda korozyon, stabilizasyonda azalma gibi potansiyel problemler görülebilmektedir ${ }^{14}$.

Ceruti ve arkadaşlarının yaptıkları bir yıllık takip çalışmasında kısa dönemde manyetik ataşman desteği kullanılarak yapılan mandibular implant destekli tam protezler hastaların beklentilerini yüksek oranda karşılamıştır. ${ }^{19}$ Benzer şekilde vakamızda hasta üst çene- deki eski tam protezini tek manyetik destekle on beş yıl gibi uzun bir süre kullanmış ancak dişlerdeki aşınma, akrilik protezdeki kaide kırığı nedeniyle protezleri yenilenmiştir. Yapılan tedavi sonrası hastanın estetik görünümü düzelmiştir ve doku desteği artırılarak protezin tutuculuk ve stabilizasyonu artırılmıştır. Tek manyetik destekle yapılan üst tam protezini hasta 1 yıldır kullanmakta olup herhangi bir şikayeti bulunmamaktadır.

Göknil Ergun Kunt ORCID ID: 0000-0002-2925-9660 Gözlem Ceylan ORCID ID: 0000-0002-2569-8068

\section{KAYNAKLAR}

1. Bansal Vishal, Kumar Sanjeev, Arunkumar Kv, Mowar Apoorva, Khare Gagan. Dental Management in Autosomal Recessive (Intermediate) Osteopetrosis: A case Report. Pediatr Dent 2010; 32: 542-5.

2. Brunning MD. Bone marrow. In: Rosai's and Ackerman's Surgical Pathology. Ed: Rosai J. 9th ed. New York: Mosby 2004; 2047- 2136.

3. Mitchell DF, Standisth SM, Fast TB. Oral Diagnosis, Oral Medicine. Third Edition, Philadelphia: 1978: 492-3.

4. Diniz G, Kayserilioğlu E, Ortaç R, Aktaş S \& Hızarcıoğlu M. Osteopetrozis: Olgu sunumu ve yeni gelişmeler. Türkiye Ekopatoloji Dergisi 2004; 10: $137-40$.

5. Baran S. Oral Patoloji. Gazi Üniversitesi Yayın No: 9, Dişhekimliği Fakültesi Yayın No: 1, Ankara: 1982: 376-9.

6. Shafer WG, Hine MK, Levy BM. A Textbook of Oral Pathology. 4th edition, W.B. Saunders Company, 1983: 684-6.

7. Dick HM, Simpson WJ. Dental Changes in Osteopetrosis. Oral Surg Oral Med Oral Pathol 1972; 34: 308-416.

8. Plotz $M$, Chalekes $H J$. Oral Involveınent in Osteopetrosis. Oral Surg 1954; 12: 16-8.

9. Aydıntuğ Yavuz S. et al. Osteopetrozis- Bir Olgu Nedeniyle. Acta Odontologica Turcica 1991; 8: 127.

10. Riley MA, Williams AJ, Speight JD, Walmsley AD, Harris IR. Investigations into the failure of dental magnets. Int J Prosthodont 1999,12: 249-54. 
11. Akın $H$, Özdemir AK. Protetik diş tedavisinde manyetik ataşmanlar. Atatürk Üniv Diş Hek Derg 2012; 6: 99-109.

12. Gillings BRD. Magnetic denture retention systems. In: Overdentures and Telescopic Prostheses. Quintessence; London 1985; 2: 121241.

13. Vrijhoef MM, Mezger PR, Van der Zell JM, Greener EH. Corrosion of ferromagnetic alloys used for magnetic retention of overdentures. ] Dent Res 1987; 66: 1456-9.

14. Riley MA, BMedSC, Walmsley AD, Harris IR. Magnets in prosthetic dentistry. Int J Prosthodont 2011; 86: 137-141.

15. Thompson IM. Magnetism as an aid to a prosthetic problem. Br J Oral Surg 1964; 2: 44-6.

16. Gillings BR. Magnetic retention for overdentures. Part II. J Prosthet Dent 1983; 49: 607-18.

17. Kroone HB, Bates JF. Overdentures with magnetic retainers. Br Dent J 1982; 152: 310-3.

18. Jonkman RE, Van Waas MA, Kalk W. Satisfaction with complete intermedite dentures and complete intermediate overdentures. A 1-year study. J Oral Rehabil 1995; 22: 791-6.

19. Ceruti P, Bryant SR, Lee JH, \& MacEntee MI. Magnet-retained implant-supported overdentures: review and 1-year clinical report. J Can Dent Assoc 2010; 76: 1-6.

\section{Yazışma Adresi}

Prof. Dr. Gözlem CEYLAN

Ondokuz Mayıs Üniversitesi

Diş Hekimliği Fakültesi

Protetik Diş Tedavisi Anabilim Dalı

TIf: 3622334567

e-mail: gceylan@omu.edu.tr 